\title{
Rice Grain Cooling Using Intermittent Adsorption and Desorption of Water Vapour: Development of a Mathematical Model
}

\author{
H.K.P.P. Kariyawasam, K.S.P. Amaratunga ${ }^{1 *}$, B.F.A. Basnayake ${ }^{1}$, \\ L.B.M.D.L. Priyadarshana ${ }^{1}$, D.D.K. Galahitiyawa ${ }^{1}$ and K.G.W.U. Karunasinghe ${ }^{1}$ \\ Postgraduate Institute of Agriculture \\ University of Peradeniya \\ Sri Lanka
}

\begin{abstract}
A one-dimensional heat and mass transfer model was developed for predicting grain temperature in a deep bed of paddy exposed to intermittent adsorption and desorption cycles and the numerical solutions of the model were approached by finite difference method. The inlet temperature and relative humidity of air were used as the model inputs. The model was validated using a laboratory scale experimental setup. The data were collected by forced air ventilation with moist air following intermittent adsorption and desorption cycles of 5 and $10 \mathrm{~min}$ in a $0.15 \mathrm{~m}$ bed of paddy in a $0.11 \mathrm{~m}$ diameter circular bin. The measured and predicted grain temperatures at different layers were in close agreement over the test period with an accuracy of $\pm 0.5^{\circ} \mathrm{C}$. Thus, the mathematical model developed can be used in predicting the rice grain temperature with similar applications.
\end{abstract}

Keywords: Heat and mass transfer, numerical solutions, paddy, grain temperature, mathematical model

\section{INTRODUCTION}

Storage temperature and relative humidity (RH) are important parameters determining seed quality and viability. The effect of storage conditions on the storability of a range of crops including cereals has been documented by Bass, 1980; Copeland \& Mc. Donald, 1985; Copeland \& Mc. Donald, 1995. Moderate temperature $\left(18-20^{\circ} \mathrm{C}\right)$ and RH (50-60\%) are ideal storage conditions for many seeds. Temperatures exceeding $25^{\circ} \mathrm{C}$ and $\mathrm{RH}$ higher than $65 \%$ have been identified as harmful for storage of many seeds (Joao Abba \& Lovato, 1999). The temperature and RH in most ambient seed stores in the dry zone of Sri Lanka are well above these values and are harmful for storage of seeds of many crops.

Ambient aeration systems lower the grain temperature only to within several degrees of the minimum ambient temperature while chilled aeration permits the short to long term storage regardless of the ambient conditions. Grain chilling is defined as the cooling of grain independent of the minimum ambient temperature by using a refrigerated air system (Maier, 1996). After the initial cooling down, re-chilling cycle are periodically run, in order to maintain the grain at the desired temperature irrespective of ambient condition. It has been shown that chilled grain storage is an efficient and profitable postharvest technology. However the question remains concerning the applicability of chilled aeration and storage in

\footnotetext{
1 Department of Agricultural Engineering, Faculty of Agriculture, University of Peradeniya, Sri Lanka

* Corresponding author: sanath.amaratunga@ gmail.com
} 
the tropics. If ambient aeration is used in tropical countries, the grain temperature in the silo generally remains above $25^{\circ} \mathrm{C}$ (Maier et al., 1993). This frequently results in pest infestation and fungal attacks requiring chemical control. Chilled aeration followed by low temperature storage has the potential to preserve the quality of paddy and other grains better in tropical countries, while reducing the postharvest losses and the need for chemical protectants and fumigants. But it should be able to justify the added expense of refrigerated aeration (Maier \& Navarro, 2001). Therefore, it is worth to evaluate an alternate system of grain cooling.

A grain evaporative cooling method was tested as an alternate method of grain cooling in this study by intermittent wetting and drying of grains using humidity controlled ambient air. The process of heat and mass transfer was mathematically simulated solving set of equations using the finite difference method. Numerical method using finite differences could be used to simulate temperature in a grain bin with fewer limitations than analytical methods (Muir et al., 1980). The accuracy of the finite difference method approaches that of the analytical solution when suitable time and space increments are chosen (Yaciuk et al., 1975). In this study, one-dimensional heat and mass transfer model was developed for predicting moisture content and grain temperature in a deep bed of paddy. The model was validated using a laboratory scale experimental setup following intermittent adsorption and desorption cycles.

\section{MATERIALS AND METHOD}

\section{Model development}

The model was based on one dimensional heat and mass transfer equations with the associated boundary conditions and was solved using finite difference method. A program was written in QBASIC language to predict the temperature, RH of air and the grain temperature through deep bed sorption. Fig. 1 shows the finite difference scheme used in this model. In the solution approach, the grain bed was divided into a finite number of horizontal layers.

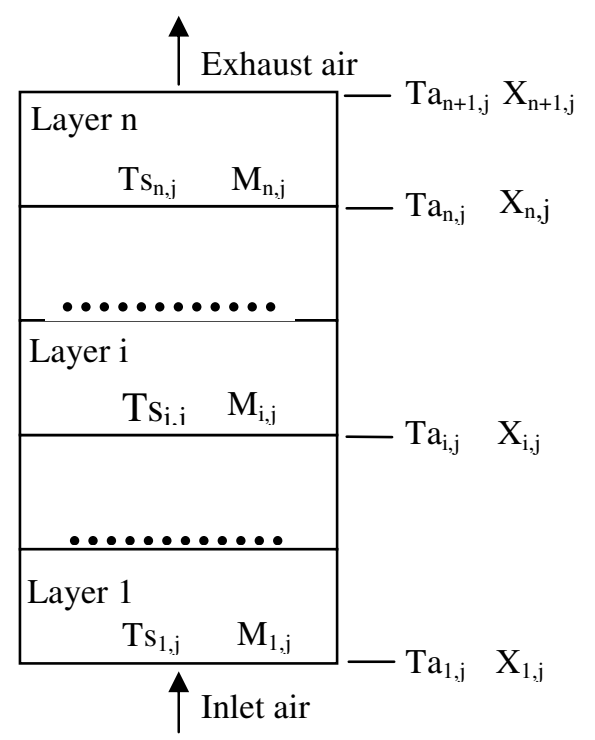

Fig. 1. Finite difference scheme 
Each layer was subjected to uniform air and grain conditions throughout the selected time interval of $6 \mathrm{~s}(\Delta \mathrm{t}=6)$. Exhaust air conditions from a layer were taken as the input air conditions to the layer immediately above. Knowing the inlet air conditions at any given layer and the initial moisture content of the layer, final air conditions and grain temperature were calculated at the end of the selected time interval. The process was repeated for each layer in the bed at a given time interval. It was assumed that the temperature and RH distribution in the grain container are uniform in the horizontal direction, hence the heat and moisture flow in the horizontal direction are negligible. At the end of each time interval, air and grain conditions were predicted during adsorption or desorption assuming that the air and grain have gone through an adiabatic process. It was also assumed that all processes are reversible and no hysteresis exists between adsorption and desorption isotherms. Several sub programs were used to calculate thermodynamic properties of moist air in a deep bed. The symbols used in this article are listed at the end of the text.

Simmonds et al. (1953) found that thin layer drying characteristics of wheat were well represented by an exponential equation, which assumed that all the resistance to moisture transfer was at the outer surface of the kernel. Becker \& Sallans (1955) suggested that the drying constant (sorption coefficient, $K$ ) is a function of the absolute temperature of the grain, in the form of an Arrhenius equation. Page equation (Equation 1) was used to describe the drying data using non-linear regression analysis in order to establish the asymptotic equilibrium moisture content, the dimensionless constant $n$, and the drying constant $K$ (Page, 1949). Murata et al. (1993) pointed out the equation 1 could be applied in the case of slow adsorption or desorption processes.

$$
\frac{\left(M-M_{e}\right)}{\left(M_{0}-M_{e}\right)}=e^{-k t^{n}}
$$

Equation 1

The drying parameters $k$ and $n$ are functions of temperature $\left({ }^{\circ} \mathrm{C}\right)$ and $\mathrm{RH}(\%)$. The expressions are given as follows (Ondier et al., 2010).

$$
\begin{aligned}
& k=-0.05303+0.0117 T-0.0011 R H \\
& n=0.6434-0.0026 T+0.0024 R H
\end{aligned}
$$

The behavior of equilibrium moisture in rough rice (paddy) is well explained by the Modified Henderson equation (Equation 2) (Thompson et al., 1968) given below and was used to calculate the equilibrium moisture content, $M_{e}$.

$$
M_{e}=\left[\ln (1-h) /\left(-K_{M} \times(T+C)\right)\right]^{\frac{1}{N}}
$$

The respective constants for rough rice approved by ASAE (1988) are given below.

$$
\begin{aligned}
& K_{M}=1.9187 \times 10^{-5} \\
& C=51.161 \\
& N=2.4451
\end{aligned}
$$

The energy required to vaporize water from a cereal grain is dependant upon its moisture content and temperature; lower the moisture content and the temperature, higher will be its 
heat of vaporization. The Clausius-Clapeyron equation (Howell \& Buckius, 1987; Moore, 1962) gives a relationship representing the change in saturated vapor pressure with the latent heat of vaporization as in Equation 3.

$$
\frac{\partial P_{s t}}{\partial T}=\frac{q}{T\left(V_{g}-V_{1}\right)}
$$

By rearranging Equation (3);

$$
q=\left(V_{g}-V_{1}\right) T\left(\frac{\partial P_{s t}}{\partial T}\right)
$$

The vapor pressure in rough rice is calculated using the equation 5;

$$
P_{s t}=h P_{s}
$$

Equilibrium RH $(h)$ is calculated using the Modified Henderson equation (Equation 2). The saturated vapor pressure $\left(P_{\mathrm{S}}\right)$ and the specific volume of water vapor $\left(\mathrm{V}_{\mathrm{g}}\right)$ are calculated using equations given in the IFC Formulation for Industrial Use (JSME, 1980).

$\partial P_{\mathrm{st}} / \partial T$ in equation 4 is obtained by differentiating Equation 5 with respect to $\mathrm{T}$ as follows:

$$
\frac{\partial P_{s t}}{\partial T}=\frac{\partial h}{\partial T} P_{s}+\frac{\partial P_{s}}{\partial T} h
$$

The term $\partial h / \partial T$ in the above equation is given by the differential of the Modified Henderson equation (Equation 2) with respect to $T$ as follows:

$$
\frac{\partial h}{\partial T}=K_{M} \cdot M_{e}^{N} \cdot e^{-M_{e}^{n} \cdot K(T+C)}
$$

Using above calculation procedure, the heat of absorbed water $\mathrm{q}$ was calculated. This is equal to the latent heat of vaporization of water in rough rice, $\sigma$.

The program flow chart of the mathematical model is shown in the Fig. 2. There are several subroutines in the program to calculate the equilibrium moisture content $\left(M_{e}\right)$, sorption coefficient $(K)$, heat of absorbed water $(q)$, and thermodynamic properties of moist air. The moisture content is calculated using following differential equation (8) derived from Equation 01 for the initial condition $M=M_{0}$ when $\mathrm{t}=0$.

$$
\frac{d M}{d T}=-K\left(M-M_{e}\right)
$$


The following differential equation is used to calculate the temperature of rough rice.

$$
\frac{\partial T_{s}}{\partial t}=\left(\frac{h_{a}}{C_{p s} \rho_{s}}\right)\left(T_{a}-T_{s}\right)-\left(\frac{K q}{C_{p s}}\right) \frac{M-M_{e}}{100}
$$

The heat transfer coefficient $\left(h_{\mathrm{a}}\right)$ in Equation 9 is calculated by employing the equation formulated by Wang et al. (1979) as:

$$
h_{a}=0.00718 G^{1.2997} \quad\left(k J / h \cdot m^{2} \cdot{ }^{\circ} \mathrm{C} \text { of medium grain rough rice }\right)
$$

The bulk density of paddy $\left(\rho_{\mathrm{s}}\right)$ at the moisture content $13 \% \mathrm{db}$ was $563 \mathrm{~kg} / \mathrm{m}^{3}$. The specific heat of rough rice $\left(C_{\mathrm{ps}}\right)$ was determined using the following equation (ASAE, 1988).

$$
C_{p s}=0.9214+0.545 M_{w}
$$

Absolute humidity was calculated using following sets of equations (11-18).

$$
\frac{\partial X}{\partial y}=-K_{2}\left(M-M_{e}\right) / 100
$$

Where:

$$
\begin{array}{ll}
K_{2}=\rho_{s} \frac{K}{G} & \\
G=V \rho_{a} & \left(k g f / \mathrm{m}^{2}\right) \\
\rho_{a}=\frac{353.3}{T_{a}} & \left(\mathrm{kgf} / \mathrm{m}^{3}\right)
\end{array}
$$




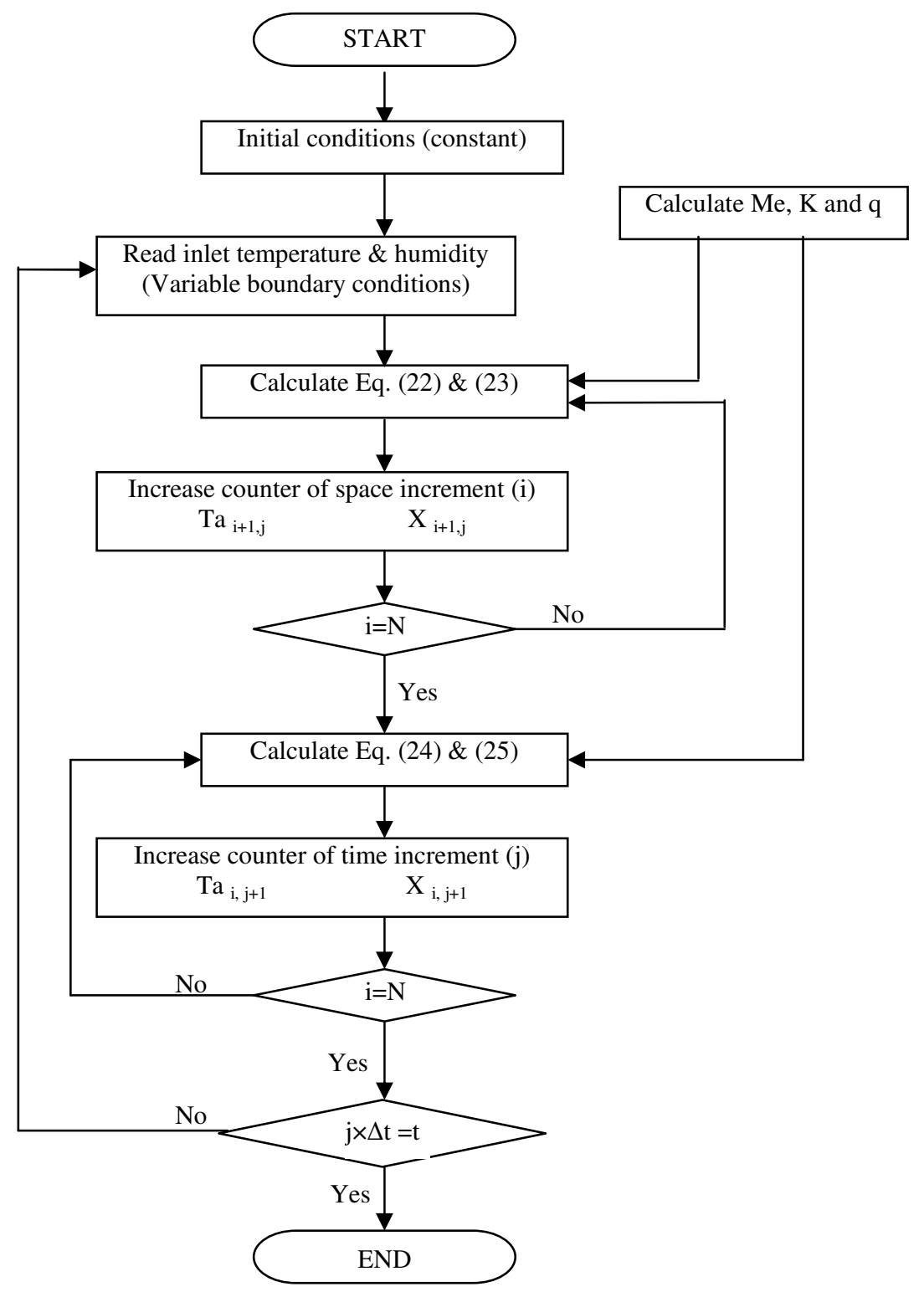

Fig. 2. Program flowchart for predicting grain temperature

The enthalpy of air is calculated as:

$$
\frac{\partial I}{\partial y}=\left(\sigma K_{2}\right)\left(M-M_{e}\right)-\left(\frac{h_{a}}{G}\right)\left(T_{a}-T_{s}\right)
$$

Where; the latent heat of vaporization of water $(\sigma)$ in paddy is calculated as shown in the preceding section. Using this enthalpy, the temperature of air is calculated as follows: 


$$
T_{a}=\left(\frac{I-\sigma X}{C_{p a}+C_{p w} X}\right)
$$

The RH of air leaving the layer is calculated as:

$$
h=\frac{p}{P_{s}}
$$

Where:

$$
p=\frac{P X}{0.622+X}
$$

Atmospheric pressure $(P)$ is taken as $101.325 \mathrm{kPa}$, while $\mathrm{P}_{\mathrm{s}}$ is calculated according to the procedures given in the IFC Formulation for Industrial Use (JSME, 1980).

The equilibrium moisture content is calculated using the Modified Henderson equation (Equation 2). The heat of absorbed water is calculated using the Equations 19 and 20.

$$
q=\left(V_{g}-V_{1}\right) T\left(\frac{\partial P_{s t}}{\partial T}\right)
$$

Where:

$$
\left(V_{g}-V_{1}\right)=R_{w} \frac{T}{p}-0.001
$$

The gas constant of water vapor $\left(R_{\mathrm{w}}\right)$ is taken as $0.461917 \mathrm{~kJ} / \mathrm{kgf} \cdot \mathrm{K}$ (Cengel \& Boles, 1989). $\partial P_{\mathrm{st}} / \partial T$ is calculated by differentiating the Henderson equation with respect to $T$ given by:

$$
\frac{\partial h}{\partial T}=K \times M_{e}^{N} \times e^{\left(-M_{e}^{N} \square K(T+C)\right.}
$$

Using Equation 12, the expression for predicting absolute humidity $\left(\mathrm{kg}-\mathrm{H}_{2} \mathrm{O} / \mathrm{kg}\right.$-dry air) written in the finite difference form is given by:

$$
X_{i+1, j}=X_{i, j}+K_{2}\left(M_{i, j}-M_{e i, j}\right) \Delta L
$$

Similarly using Equation 15, the enthalpy of air (kJ/kg-dry air) can be written as:

$$
I_{i+1, j}=I_{i, j}+\left(\sigma K_{2}\right)\left(M_{i . j}-M_{e i . j)}\right) \Delta L-\left(\frac{h_{a}}{G}\right)\left(T_{a_{i, j}}-T_{s i . j}\right) \Delta L
$$

Using Equation 8, the following finite difference form equation is used to calculate the moisture content $\left(M_{\mathrm{i}}\right)$ of rough rice.

$$
M_{i, j+1}=M_{i, j}-K\left(M_{i, j}-M_{e i, j}\right) \Delta t
$$

The temperature of rough rice is calculated using the following equation. 


$$
T_{s_{i, j+1}}=T_{s_{i, j}}+\left(\frac{h_{a}}{C_{p s} \rho}\right)\left(T_{a_{i, j}}-T_{s_{i, j}}\right) \Delta t-\left(\frac{K q}{C_{p s}}\right)\left(M_{i, j}-M_{e_{i, j}}\right) \Delta t
$$

In the model,

$$
\begin{aligned}
& \Delta L(\text { Element thickness })=0.05 \mathrm{~m} \\
& \Delta t \text { (Time increment })=6 \mathrm{~s}
\end{aligned}
$$

Initial and boundary conditions are as follows:

. $\mathrm{Ts}_{\mathrm{i}, \hat{\gamma}}=\mathrm{Temperature}$ of paddy at the beginning of the test

I.C. $=\left\{\mathrm{Ms}_{\mathrm{i}, 0}=\right.$ Moisture content of paddy at the beginning of the test

B.C. $=\left\{\begin{array}{c}\mathrm{Ta}_{1, \mathrm{j}}=\text { Initial temperature of air from observed data } \\ \mathrm{Xs}_{1, \mathrm{j}}=\text { Initial } \mathrm{RH} \text { of air from observed data }\end{array}\right.$

\section{Validation of the model}

\section{Materials}

The paddy variety of BG 354 harvested from Dodangolla University Experimental Station, Faculty of Agriculture, University of Peradeniya, in 2011Yala season (April to August) was used for the experiment. The initial moisture content of paddy was $23 \%$ w.b. The samples were manually threshed by stripping the grains from the panicle and shade dried for 03 days until the moisture content reaches to $12 \%$ w.b. The bulk sample was packed in polyethylene sacks and stored at $5{ }^{\circ} \mathrm{C}$ until time for the tests. Before starting each experiment, paddy samples were kept at room temperature for 10 hours. The initial moisture content was determined by air oven dry method (PRECISION, model:26, USA)by drying three $10 \mathrm{~g}$ whole grain samples at $135^{\circ} \mathrm{C}$ for 24 hours (Ban \& Susawa, 1973).

\section{Experimental set-up and the procedure}

The experimental apparatus is illustrated in the Fig. 3. Paddy was filled into $0.11 \mathrm{~m}$ diameter PVC (0.003 m thick) circular pipe up to $0.15 \mathrm{~m}$ height. Paddy sample was then ventilated with ambient air for $15 \mathrm{~min}$ followed by 5 and $10 \mathrm{~min}$ saturated air ventilation. Saturated air for ventilation was produced by saturating ambient air with water vapor produced by an ultrasonic humidifier (Mammy, MUH 4400, Japan). The testing conditions are listed in the Table 1. The temperature of air at the inlet and outlet, and the grain temperatures at 0.025 (L1), 0.075 (L2), 0.125 (L3) $\mathrm{m}$ heights in the sample bed were measured using ' $\mathrm{T}$ ' type thermocouples (Copper- Constantan; range $-62{ }^{\circ} \mathrm{C}$ to $125{ }^{\circ} \mathrm{C}$; accuracy $\pm 1{ }^{\circ} \mathrm{C}$ ) and were recorded continuously throughout the test period. 
Table 1. Adsorption and desorption time durations tested in the trials

\begin{tabular}{ccc}
\hline Trial & $\begin{array}{c}\text { Duration of ventilation } \\
\text { with 100\% RH (min) }\end{array}$ & $\begin{array}{c}\text { Trial duration } \\
(\mathbf{m i n})\end{array}$ \\
\hline 1 & 10 & 26.5 \\
2 & 10 & 25.0 \\
3 & 10 & 25.0 \\
4 & 05 & 37.5 \\
5 & 05 & 25.0 \\
6 & 05 & 25.0 \\
\hline
\end{tabular}

The RH of air was measured at the inlet, exhaust and ambient air using RH sensors (TDK: CHS-UGR, Japan; accuracy $\pm 5 \%$; range 5-95\%). The moisture content was measured by air oven method $\left(135^{\circ} \mathrm{C}\right.$ for $\left.24 \mathrm{~h}\right)$ at the beginning of the test and at the end of the test by drawing $5 \mathrm{~g}$ samples from each layer. The total weight of the column and rough rice was measured at the beginning and at the end of the each test.

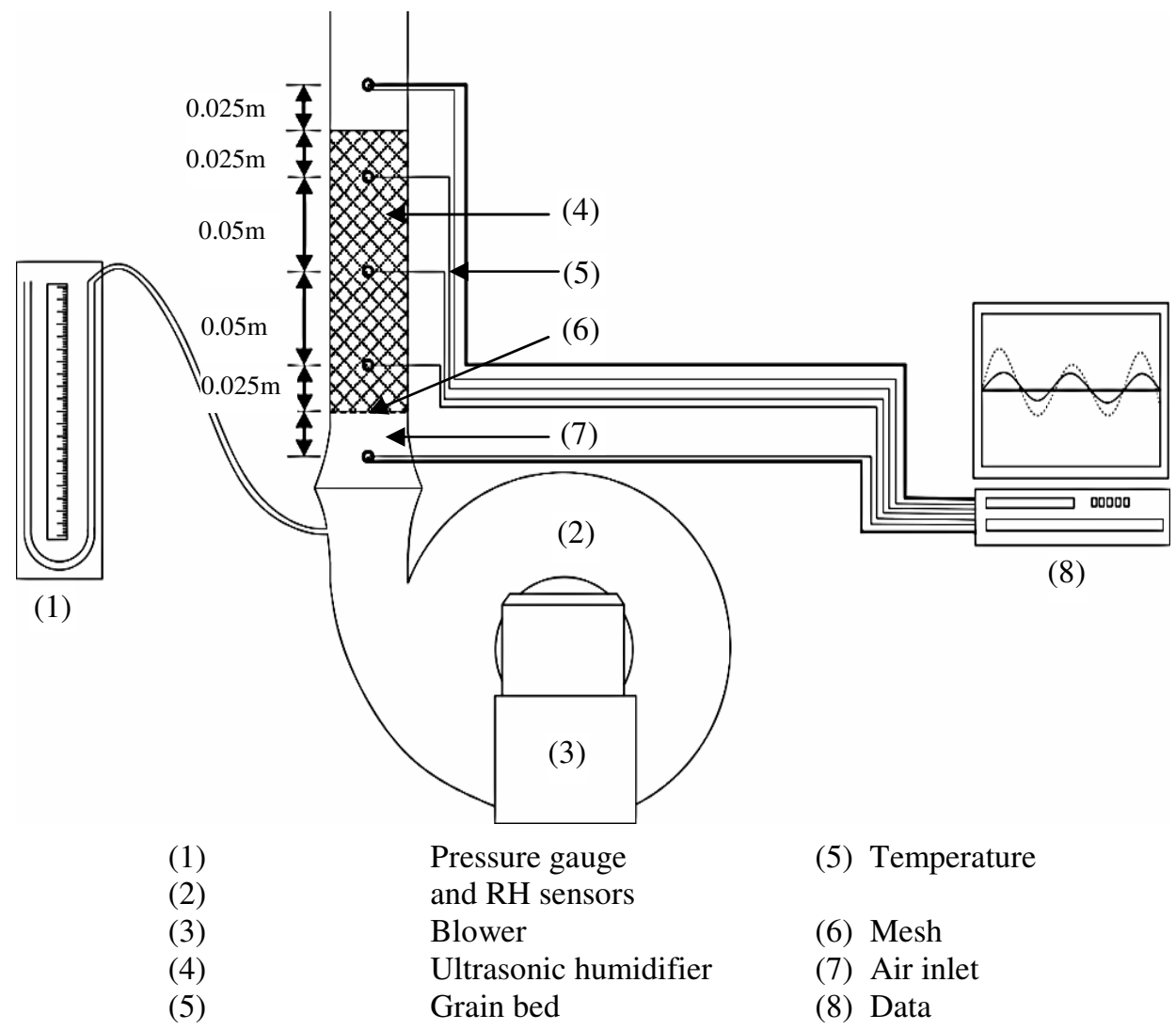

Fig. 3. Experimental set up for intermittent adsorption and desorption of water vapor 


\section{RESULTS AND DISCUSSION}

With the introduction of saturated air, the temperature of paddy grains increases. This is because of condensation of water on grains releasing the latent heat of condensation to the grains. The latent heat of condensation is partly used for the temperature rise in the grain and the rest loses to the air by convection. When the humidification stops, it starts to dry grains taking the latent heat of vaporization from the grain. The computational model used to simulate the process includes both these processes. Since some of the energy of condensation already dissipated to the air stream by convection, vaporizing same amount of water (as condensed) reduces the grain temperature lower than its initial temperature. Fig. 4 shows the observed rice grain temperature during $5 \mathrm{~min}$ of adsorption followed by desorption. The Tables 2 and 3 show the paddy grain temperature reduction and moisture gain during $10 \mathrm{~min}$ and $5 \mathrm{~min}$ of wetting respectively. Fig. 5 shows the observed data and the model simulated rice grain temperature at different layers for 05 min of adsorption.

The trials 1, 2 and 3 were conducted for one wetting cycle of 10 min. In the trial 1, all three layers showed $3.5^{\circ} \mathrm{C}$ temperature reductions. This temperature reduction was observed with a time lag of $918 \mathrm{sec}(15 \mathrm{~min}), 1084 \mathrm{sec}(18 \mathrm{~min})$ and $1200 \mathrm{sec}(20 \mathrm{~min})$ from starting of the humidification in the $1^{\text {st }}, 2^{\text {nd }}$ and the $3^{\text {rd }}$ layers respectively. During the trial period of 20 min, the moisture gain in the $1^{\text {st }}$ layer was $0.42 \%$ w.b. and almost no moisture gain was observed in the $2^{\text {nd }}$ and $3^{\text {rd }}$ layers.

In the $2^{\text {nd }}$ trial, the temperature reductions in the $1^{\text {st }}, 2^{\text {nd }}$ and the $3^{\text {rd }}$ layers were $3.70,3.78$ and $3.28{ }^{\circ} \mathrm{C}$ respectively. These minimum temperatures were observed at $1034 \mathrm{sec}(17 \mathrm{~min})$, $1164 \mathrm{sec}(19 \mathrm{~min})$ and $1216 \mathrm{sec}(20 \mathrm{~min})$ after starting of the humidification. The moisture gain was $0.3 \%$ w.b. in the $1^{\text {st }}$ layer and it was $0.1 \%$ w.b. in the $2^{\text {nd }}$ and $3^{\text {rd }}$ layers.

The $3^{\text {rd }}$ trial also showed a similar response in temperature reduction and moisture gain. Temperature reduction of $4.24,4.33$ and $4.26{ }^{\circ} \mathrm{C}$ was observed in the $1^{\text {st }}, 2^{\text {nd }}$ and $3^{\text {rd }}$ layers respectively. These minimum temperatures were observed at $990 \mathrm{sec}(16.5 \mathrm{~min}), 1160 \mathrm{sec}$ (19 $\mathrm{min}$ and $1168 \mathrm{sec}(19.5 \mathrm{~min})$ from the initiation of the humidification. The moisture gain in the $1^{\text {st }}$ layer was $0.4 \%$ w.b. while it was $0.1 \%$ w.b. in the other two layers.

Table 2. Temperature reduction and moisture gain of paddy with $10 \mathrm{~min}$ adsorption followed by desorption

\begin{tabular}{|c|c|c|c|c|c|c|c|c|}
\hline Trial & Layer & $\begin{array}{c}\text { Initial } \\
\text { temp. } \\
\left({ }^{\circ} \mathrm{C}\right)\end{array}$ & $\begin{array}{c}\text { Min. } \\
\text { temp. } \\
\left({ }^{\circ} \mathrm{C}\right)\end{array}$ & $\begin{array}{l}\text { Temp. } \\
\text { reduction } \\
\left({ }^{\circ} \mathrm{C}\right)\end{array}$ & $\begin{array}{l}\text { Time to reach } \\
\text { minimum } \\
\text { temp. from } \\
\text { humidification } \\
\text { (s) }\end{array}$ & $\begin{array}{c}\text { Initial } \\
\text { MC } \\
\text { (\%w.b.) }\end{array}$ & $\begin{array}{c}\text { Final } \\
\text { MC } \\
(\% \text { w.b. })\end{array}$ & $\begin{array}{c}\text { MC } \\
\text { gain } \\
(\% \text { w.b. })\end{array}$ \\
\hline \multirow[t]{3}{*}{1} & 1 & 28.07 & 24.52 & 3.55 & 918 & \multirow[t]{3}{*}{12.18} & 12.60 & 0.42 \\
\hline & 2 & 28.41 & 24.85 & 3.56 & 1084 & & 12.24 & 0.06 \\
\hline & 3 & 28.73 & 25.25 & 3.48 & 1200 & & 12.22 & 0.04 \\
\hline \multirow[t]{3}{*}{2} & 1 & 28.12 & 24.42 & 3.70 & 1034 & \multirow[t]{3}{*}{12.34} & 12.64 & 0.30 \\
\hline & 2 & 28.52 & 24.74 & 3.78 & 1164 & & 12.43 & 0.09 \\
\hline & 3 & 28.80 & 25.52 & 3.28 & 1216 & & 12.40 & 0.06 \\
\hline \multirow[t]{3}{*}{3} & 1 & 28.12 & 23.88 & 4.24 & 990 & \multirow[t]{3}{*}{12.42} & 12.85 & 0.43 \\
\hline & 2 & 28.49 & 24.16 & 4.33 & 1160 & & 12.49 & 0.07 \\
\hline & 3 & 28.80 & 24.54 & 4.26 & 1168 & & 12.54 & 0.12 \\
\hline
\end{tabular}


Table 3. Temperature reduction and moisture gain with 05 min of adsorption followed by desorption

\begin{tabular}{|c|c|c|c|c|c|c|c|c|}
\hline Trial & Layer & $\begin{array}{c}\text { Initial } \\
\text { temp. } \\
\left({ }^{\circ} \mathbf{C}\right)\end{array}$ & $\begin{array}{c}\text { Min. } \\
\text { temp. } \\
(\mathrm{C})\end{array}$ & $\begin{array}{l}\text { Temp. } \\
\text { reduction } \\
(\mathbf{C})\end{array}$ & $\begin{array}{c}\text { Time to reach } \\
\text { minimum } \\
\text { temp. from } \\
\text { humidification } \\
\text { (s) }\end{array}$ & $\begin{array}{c}\text { Initial } \\
\text { MC } \\
\text { (\%w.b.) }\end{array}$ & $\begin{array}{c}\text { Final } \\
\text { MC } \\
(\% \text { w.b. })\end{array}$ & $\begin{array}{c}\text { MC } \\
\text { gain } \\
(\% \text { w.b. })\end{array}$ \\
\hline \multirow[t]{3}{*}{4} & 1 & 29.19 & 26.07 & 3.12 & 730 & 12.30 & 12.40 & 0.10 \\
\hline & 2 & 29.13 & 26.27 & 2.90 & 870 & & 12.22 & -0.08 \\
\hline & 3 & 29.30 & 26.57 & 2.73 & 1066 & & 12.23 & -0.07 \\
\hline \multirow[t]{3}{*}{5} & 1 & 28.00 & 25.39 & 2.61 & 556 & 12.09 & 12.25 & 0.16 \\
\hline & 2 & 28.16 & 25.73 & 2.43 & 692 & & 12.17 & 0.08 \\
\hline & 3 & 28.37 & 26.61 & 1.76 & 726 & & 12.11 & 0.02 \\
\hline \multirow[t]{3}{*}{6} & 1 & 29.34 & 27.22 & 2.12 & 748 & 12.56 & 12.73 & 0.17 \\
\hline & 2 & 29.75 & 27.70 & 2.05 & 850 & & 12.54 & -0.02 \\
\hline & 3 & 29.94 & 28.42 & 1.52 & 878 & & 12.50 & -0.06 \\
\hline
\end{tabular}

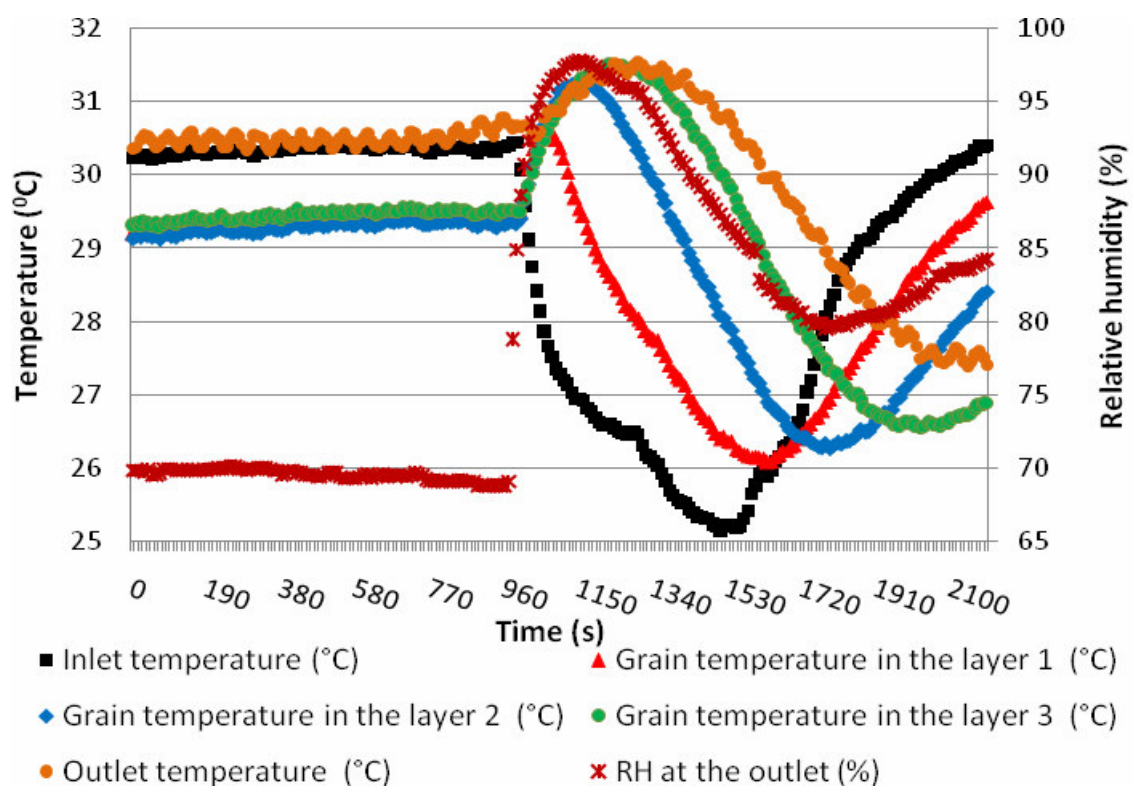

Fig. 4. The observed rice grain temperature in the three layers, inlet and outlet, and RH at the outlet during 05 min of adsorption followed by desorption 


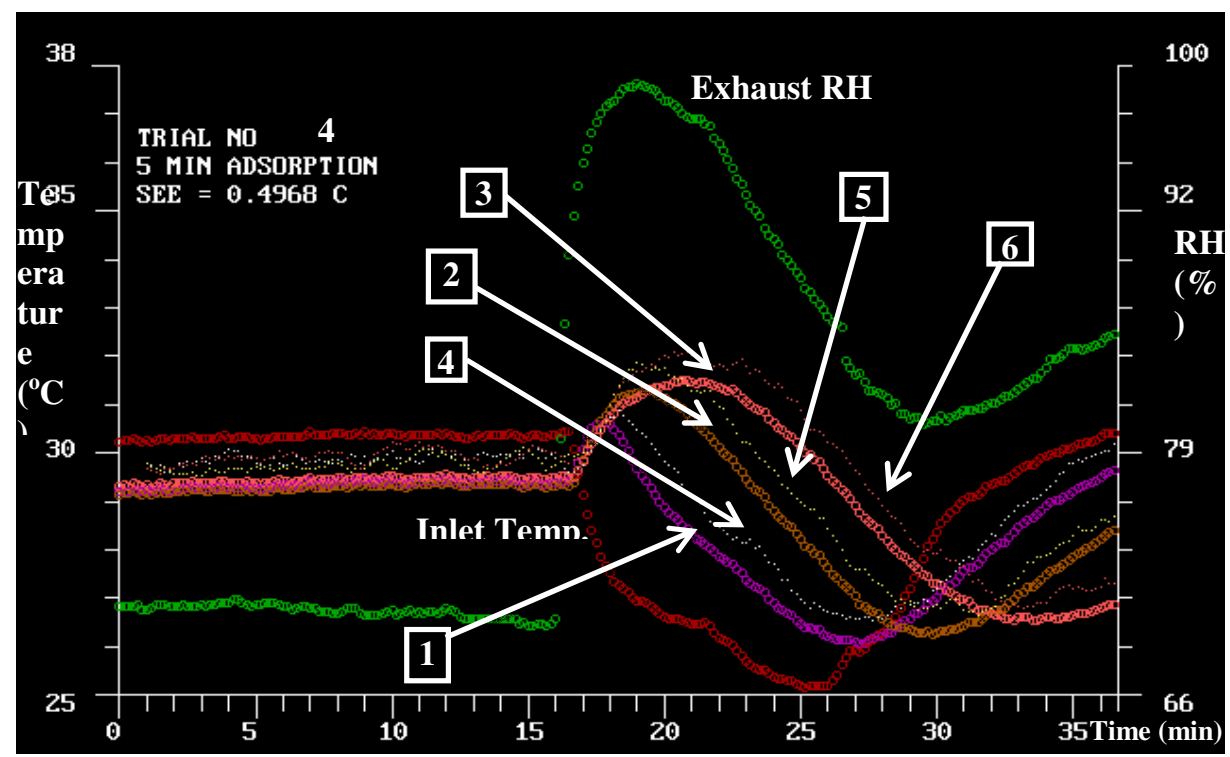

1. Layer 1 observed grain temperature 4 . Layer 1 simulated grain temperature by the model

2. Layer 2 observed grain temperature 5 . Layer 2 simulated grain temperature by the model

3. Layer 3 observed grain temperature 6 . Layer 3 simulated grain temperature by the model

Fig. 5. Observed and the model simulated paddy grain temperature at different layers by adsorption of water vapor for 5 min followed by desorption

The trials 4, 5 and 6 were conducted for one wetting cycle of 05 min. In the $4^{\text {th }}$ trial the layers 1,2 and 3 showed a temperature reduction of $3.1,2.9$ and $2.7{ }^{\circ} \mathrm{C}$ respectively. The minimum temperature was reached at $730 \mathrm{sec}(12 \mathrm{~min}), 870 \mathrm{sec}(14.5 \mathrm{~min})$ and $1066 \mathrm{sec}(18$ min) after the initiation of the wetting. Only the bottom layer showed $0.1 \%$ w.b. increase in moisture. The other two layers lost almost $0.1 \%$ w.b. moisture during the trial period. The $5^{\text {th }}$ and $6^{\text {th }}$ trials showed a similar pattern in temperature reduction and moisture gain.

The model was capable of predicting the grain temperature with an accuracy of $\pm 1 \%$ for the tested period of $30 \mathrm{~min}$. For the six tests conducted, the standard error of estimate by the mathematical model developed was in the range of 0.1 to $0.5 \mathrm{C}$. Therefore the developed model can be used in predicting the paddy grain temperature during adsorption and desorption of water vapor.

\section{CONCLUSION}

A grain evaporative cooling mechanism by ventilating paddy with saturated air followed by desorption with ambient air was tested and proved to be successful. A temperature reduction over $2{ }^{\circ} \mathrm{C}$ was observed when paddy was exposed to saturated air for $5 \mathrm{~min}$ followed by desorption. In 10 min exposure to saturated air followed by desorption showed over $3.5^{\circ} \mathrm{C}$ temperature reduction. The mathematical model developed for predicting the paddy temperature followed well with the observed data with a standard error of estimate ranging from 0.1 to $0.5^{\circ} \mathrm{C}$. 


\section{NOMENCLATURE}

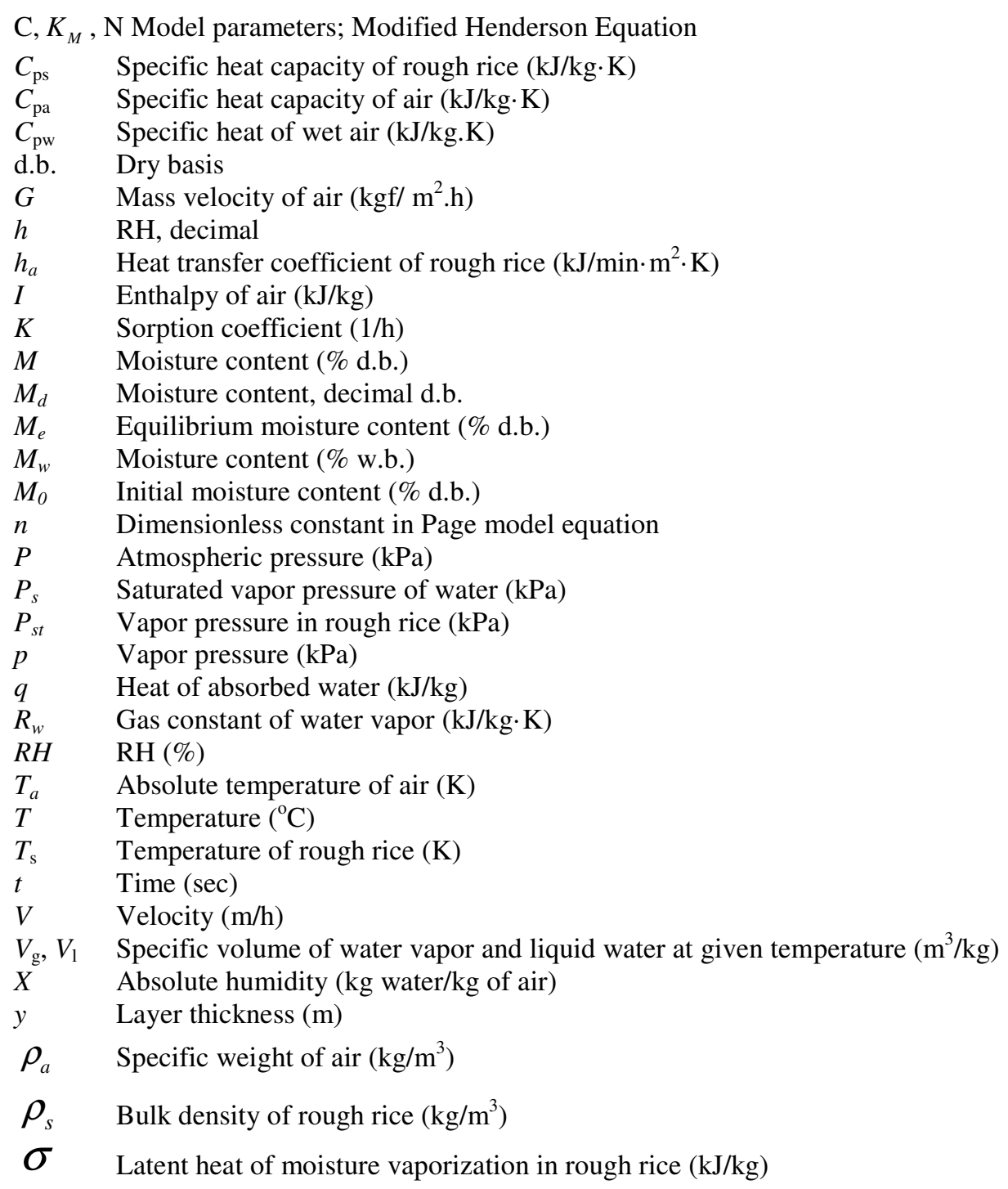

\section{REFERENCES}

ASAE (1988). Agricultural Engineers' hand book. Am. Soc. Agr. Eng., St. Joseph, MI. $35^{\text {th }}$ ed., pp. 294 - 306.

Bass, L. (1980). Seed viability during long term storage, Horticultural Review, 2: 117- 14.

Ban, T. and Susawa, K. (1973). Study on grain moisture content measurements by air oven methods (II): Investigation on the methods without the apparent loss of dry matter. J. of Agric. Mach., 35(2), 406 - 415. 
Becker, H.A. and Sallans, M.A. (1955). A study of internal moisture movement in the drying of wheat kernel. Cereal Chem. 32, 212 - 226.

Cengel, Y.A. and Boles, M.A. (1989). Molar mass, gas constant and critical-point properties. In "Thermodynamic and Engineering Approach", McGraw-Hill, $2^{\text {nd }}$ ed., p. 868.

Copeland, L.O. and McDonald, M.B. (1985). Principals of seed Science and Technology, 369. Burgess Publishing Company. Minneapolis, Minnesota.

Copeland, L.O. and McDonald, M.B. (1995). Principals of seed science and technology, Third edition Chapman and Hall. p.409.

Howell, J.R. and Buckius, R.O. (1987). Fundamentals of engineering thermodynamics. McGraw Hill, Newyork.

Joao Abba, E. and Lovato, A. (1999). Effect of seed storage temperature and RH on maize (Zea mays L.) seed viability and vigor. Seed Sci. and Tech. 27,101 - 114.

JSME (1980). International Formulation Committee of Sixth international Conference on the Properties of Steam. IFC Formulation for Industrial Use (1967). SI JSME Steam Tables, pp. 106-119.

Maier, D.E. (1996). Preservation of grain with aeration, 71, 379 - 397. In Champ, B. R., Highley, E. and Johnson, G. I. (Ed.) Grain drying in Asia: Proceedings of an International Conference held at the FAO Regional Office for Asia and Pacific, Bangkok, Thai-land. ACIAR Proceedings,

Maier D.E. and Navarro S. (2001). Chilling of grain by refrigerated air: The mechanics and physics of modern grain aeration management. Navarro, S. and Noyes, R.T. (Ed.), CRC Press.

Maier, D.E., Bakker-Arkema, F.W., and Ilangantileke, S.G. (1993). Ambient and chilled paddy aeration under Thai conditions, Agric. Eng. J., 2(1), 15 - 33.

Moore, W.J. (1962). Physical chemistry, Prentice-Hall, Englewood Cliffs, $3^{\text {rd }}$ ed, p.27.

Muir, W.E., Fraser, M. and Sinha, R.N. (1980). Simulation model of two dimensional heat transfer in controlled atmosphere grain bins. pp. 385-398. In: Shejbal. S. (Ed.) Controlled atmosphere storage of grain. Elsevier Sci. Pub. Co.

Murata, S., Enomoto, T. and Miyauchi, K. (1993). Adsorption characteristics of thin silicagel layer and simulation in a fixed layer. Jpn. Soc. Agric. Mach. 55(3), 41 - 49.

Ondier, G.O., Siebenmorgen, T.J. and Mauromoustakos, A. (2010). Low temperature, low RH drying of rough rice. Food Eng. 100, pp. 545-550.

Page, G., (1949). Factors influencing the maximum rates of air drying shelled corn in thin layers. Unpublished master thesis, Purdue University, Lafayette, IN.

Simmonds, W.H.C., Ward, G.T. and McEwen, E. (1953). The drying of wheat grain part I: The mechanism of drying. Trans. Inst. Chem. Eng., 31, 265 - 278. 
Thompson, T.L., Peart, R.M. and Foster, G.H. (1968). Mathematical simulation of corn drying: a new model. Trans. of the ASAE, 11, pp 582 - 586.

Yaciuket, G., Muir, W.E. and Sinha, R.N. (1975). A simulation model of temperatures in stored grain. Agric. Eng. Res. 20, 245 - 258.

Wang, C.Y., Rumsey, T.R. and Singh, R.P. (1979). Convective heat transfer coefficient in a packed bed of rice. ASAE Paper No. 79 - 3040.

Zuritz, C.A. and Singh R.P. (1985). An equation to compute the heat of evaporation for rough rice during drying.Dry. Tech. 3(3), 421 - 435. 